\title{
Article
}

Mycosphere

\section{Amylosporus guaraniticus sp. nov. (Wrightoporiaceae, Russulales) a new neotropical species from Paraguay}

\author{
Campi $\mathbf{M}^{1}$, Maubet $\mathbf{Y}^{1}$, Grassi $\mathbf{E}^{2}$ and Robledo GL $\mathbf{L}^{3,4}$ \\ ${ }^{1}$ Universidad Nacional de Asunción. Laboratorio de Análisis de Recursos Vegetales Área Micología-Facultad de \\ Ciencias Exactas y Naturales \\ ${ }^{2}$ Instituo Misionero de Biodiversidad (IMiBio) \\ ${ }^{3}$ Instituto Multidisciplinario de Biología Vegetal - CONICET. Universidad Nacional de Córdoba C.C. 495,5000 \\ Córdoba, Córdoba, Argentina \\ ${ }^{4}$ Fundación FungiCosmos, Av. General Paz 154, $4^{\circ}$ piso, oficina 4, Córdoba, Argentina;
}

Campi M, Maubet Y, Grassi E, Robledo G. 2017 - Amylosporus guaraniticus sp. nov. (Wrightoporiaceae, Russulales) a new neotropical species in Paraguay. Mycosphere 8(6), 10601070, Doi 10.5943/mycosphere/8/6/6

\begin{abstract}
Amylosporus guaraniticus is described as a new species from Paraguay based on morphological characters and molecular evidence based on ITS and LSU markers. The species is characterized by its annual, pileate basidiomata, poroid hymenophore, a dimitic hyphal system with simple septate and double to multiple clamped generative hyphae and asperulated, amyloid basidiospores (4-6.5 $\times$ 3-4.5 $\mu \mathrm{m})$. An identification key to Amylosporus species is presented.
\end{abstract}

Key words - fungal diversity, molecular phylogeny, neotropical polypores, taxonomy

\section{Introduction}

Amylosporus Ryvarden was erected to accommodate A. campelli (Berk.) Ryvarden characterized by having finely asperulate amyloid basidiospores, and a dimitic hyphal system with generative hyphae presenting both simple and multi-clamped septa (Ryvarden 1973).

The most recent and comprehensive phylogenetic work placed the genus within Wrightoporiaceae Jülich as a sister clade of Wrightoporia Pouzar (Chen et al. 2016). Only five species have been included in phylogenetic analyses, i.e. A. bracei (Murrill) A. David \& Rajchenb., A. campbellii (Berk.) Ryvarden, A. casuarinicola (Y.C. Dai \& B.K. Cui) Y.C. Dai, Jia J. Chen \& B.K. Cui, A. rubellus (Y.C. Dai) Y.C. Dai, Jia J. Chen \& B.K. Cui and A. succulentus Jia J. Chen \& L.L. Shen, and they conform a monophyletic clade (Chen et al. 2016). This phylogenetic circumscription of the genus maintains the original diagnostic morphological characters (Ryvarden 1973).

Amylosporus campbelli has been considered a "pantropical" species, widely distributed in tropical and subtropical regions of the world (Ryvarden \& Johansen 1980). However it has been shown that $A$. campbelli involves more than one species, and new taxa have been segregated as $A$. succulentus (Dai 2007, Chen \& Shen 2014). Amylosporus campbellii has been recorded in South America from Argentina and Guyana (David \& Rajchenberg 1985, Robledo \& Rajchenberg 2007). Morphological and phylogenetic analysis of specimens collected in Paraguay purportedly 
corresponding to A. campbellii showed to represent a new species here described as Amylosporus guaraniticus sp. nov.

\section{Materials \& Methods}

\section{Morphological analyses}

Studied specimens are kept at Laboratorio de Análisis de Recursos Vegetales, Área Micología, Universidad Nacional de Asunción FACEN herbarium and Mycoteca of Fundación FungiCosmos (FCOS). For the study of the specimens, macroscopic and microscopic observations were made on fresh and dried materials following Gómez Montoya et al. (2017). Microscopic features, measurements and drawings were made from slide preparations rehydrated with $\mathrm{KOH} 3-$ $5 \%$, stained with congo red, phloxine and melzer's reagent under light microscope. Measurements of basidiospores followed a standard sampling of thirty measurements $(n=30)$. The following abbreviations were used for basidiospore measurements $\mathrm{X}=$ arithmetic mean, $\mathrm{Q}=$ arithmetic mean the ratio of length/width, $\mathrm{N}=$ number of specimens.

\section{DNA extraction, amplification and sequencing}

Total DNA was extracted from small pieces of dried basidiomata triturated with LyserMjolnir 1.0 Franchi-Robledo TM 2012 for 2 o 3 min. The powder was transferred to an Eppendorf-tubes and mixed with lysis buffer consisting of $2 \% \mathrm{CTAB}$, at $65 \mathrm{C}$ for at least 1 hour. Chloroform extraction was done once, and DNA precipitated with isopropanol (Doyle 1991). Amplification of the ITS and nucLSU regions was performed using ITS8/ITS6 (including ITS1, 5.8S and ITS2) and LR0R/LR5 that for nLSU (White et al. 1990, Gardes \& Bruns 1993, Hopple \& Vilgalys 1999). PCR was performed following the programs and protocols indicated by Gomez Montoya et al. 2017. PCR products were visualized with $1.5 \%$ agarose gel electrophoresis. Amplified products were purified and then sequenced in both directions. In all cases, the same primer used in the amplification was used for sequencing. The cycle-sequencing was performed in an Applied Biosystems 3730xl DNA Analyser in MacroGen Ltd. (South Korea). For the analyzes were used the newly generated sequences, and including related sequences downloaded from GenBank (Table 1).

Two sequences of interest were obtained for our analysis. Additionally 26 sequences obtained from GenBank were included in the analysis. DNA sequences were edited with the software program BioEdit sequence alignment editor, version 7.0.5.3 (Hall 1999) and assembled using a text editor. The dataset was aligned using Muscle (Thompson et al. 1997). The alignment obtained was manually examined and adjusted with MEGA 6 (Tamura et al. 2013) and finally deposited at TreeBase (Submission ID 21248). To select the best phylogenetic model MEGA 6 was used (Tamura et al. 2013). A bootstrap analysis was performed with 1000000 replications. Bayesian inference under the K2 + G model (Nei \& Kumar 2000) was calculated with MrBayes v. 3.2.5 (Huelsenbeck \& Ronquist 2001). Two Markov chains were run from random starting trees for 50 million generations. The first 5000 generations were discarded as burn-in.

\section{Results}

\section{Phylogenetic analyses}

The complete alignment of the ITS region included 947 positions, including gaps, whereas LSU region included 571 positions including gaps. According to the preceding analyses, $\mathrm{K} 2+\mathrm{G}$ was chosen as the best-fit substitution model to the ITS dataset in the Bayesian Inference, with the following base frequencies A (0.250), C (0.250), G (0.250), $\mathrm{T}(0.250)$ and a gamma distribution shape parameter of 0.31 . The nucleotide substitution rates estimated according to this model were $\mathrm{A} / \mathrm{G}=0.176, \mathrm{~A} / \mathrm{T}=0.037, \mathrm{C} / \mathrm{G}=0.37, \mathrm{C} / \mathrm{T}=0.176$ and $\mathrm{G} / \mathrm{T}=0.37$. According to the preceding analyses, $\mathrm{K} 2+\mathrm{G}$ was chosen as the best-fit substitution model to the LSU dataset in the Bayesian Inference, with the following base frequencies A (0.250), $\mathrm{C}$ (0.250), $\mathrm{G}(0.250), \mathrm{T}(0.250)$, proportion of 
invariable sites of 0.025 . The nucleotide substitution rates estimated according to this model were $\mathrm{A} / \mathrm{C}=0.012, \mathrm{~A} / \mathrm{G}=0.226, \mathrm{~A} / \mathrm{T}=0.012, \mathrm{C} / \mathrm{G}=0.012, \mathrm{C} / \mathrm{T}=0.226, \mathrm{G} / \mathrm{T}=0.12$. The two independent runs of Bayesian analysis converged to stable values after 50000000 generations (average standard deviation of split frequencies $=0.001267$; average potential scale reduction factor $=1.000)$, a total of $25 \%$ of the sampled trees were discarded as burn-in. The remaining trees were used to construct the $50 \%$ majority-rule consensus trees (Figure 1).

The studied materials grouped in a strongly supported clade $(\mathrm{BPP}=1.0)$ constituting an independent phylogenetic lineage which we describe below as a new species, Amylosporus guaraniticus. Amylosporus campbellii, represented by four neotropical specimens grouped with the new species conforming a strongly supported clade $(\mathrm{BPP}=1)$. A group of three paleotropical species consisting of Amylosporus succulentus from China and two unnamed species from Tanzania and India respectively conform a sister group of neotropical species. These sisters clades are strongly supported clade $(\mathrm{BPP}=1)$, and hereafter called 'Amylosporus campbelli clade'. Amylosporus casuarinicola, A. bracei and A. rubellus, relationships are not well resolved, however.

Amylosporus guaraniticus Campi \& Robledo sp. nov.

Figs 2-3

MycoBank number MB821985; Facesoffungi number: FoF 03568

Etymology - Guaraniticus refers to the area where Guaraní indigenous ethnicity inhabited, mainly Eastern Paraguay and NE Argentina.

Holotypus. Paraguay, San Lorenzo, University Campus, 03.III.2016, leg. M. Campi 106 (FACEN 3422).

Basidiomata annual, sessile, imbricate, semicircular, broadly adhered to the surface, $23 \times 12$ $\times 5 \mathrm{~cm}$, fleshy and soft when fresh, corky when dry. Pileal surface glabrous to velvety, soft when fresh, whitish to pale brown, with chestnuts areas towards the base which become dark brown or blackish at maturity. Margin sterile, round, whitish to cream when fresh, acute and light brown when dry. Pores angular 2-3 per mm, dissepiments entire occasionally lacerate, pore surface whitish when fresh becoming cream to light brown when dry. Context homogeneous, fleshy, white to cream when fresh, corky and light brown when dry, up to $42 \mathrm{~mm}$. Tube layer concolorous with the context up to $10 \mathrm{~mm}$ thick. Hyphal system dimitic, generative hyphae thin-walled, 4-6.5 $\mu \mathrm{m}$ diam; the context composed of with generative hyphae 6-14 $\mu \mathrm{m}$ diam., with simple septa and double or multiple clamp connections, gloeopleurous hyphae present. Skeletal hyphae restricted to the tubes, thick-walled, 3-8 $\mu \mathrm{m}$ diam, branched, flexuous, IKI-. Basidia clavate, 10-25 $\times 5-8 \mu \mathrm{m}$, with four sterigmata 2-6 $\mu \mathrm{m}$ long. Basidiospores ellipsoid, (3.8)4-5.5(6.5) $\times(2.5) 3-4(4.5) \mu \mathrm{m}$, $\mathrm{X}=4.6 \times 3.4 \mu \mathrm{m}, \mathrm{Q}=1.4, \mathrm{~N}=2$, hyaline, thin- to slightly thick-walled, finely asperulate, with a central guttule, strongly amyloid.

Known distribution - So far know from type locality. Records of A. campbellii in South America must be reviewed in order to confirm their identity, see discussion.

Material examined - Paraguay, Central Department, San Lorenzo city, Universidad Nacional de

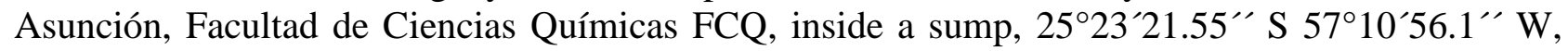
245 m a.s.l., 03 March 2016, M. Campi, 106 (FACEN 003422, HOLOTYPE). Ibid, Facultad de Arquitectura, Diseño y Arte, coming out from between the brick board against the floor ,

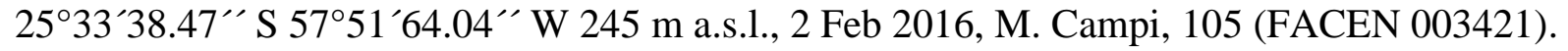

\section{A key to Amylosporus species}

1. Basidiomata stipitate 2

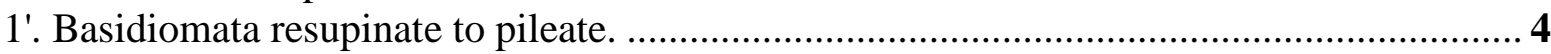

2. Skeletal hyphae non-dextrinoid. A. campbellii

2'. Skeletal hyphae dextrinoid.

3. Pores 3-6/mm; known from NE Brazilian semiarid región A. auxiliadorae 
5. Skeletal hyphae IKI-

A. ryvardenii

5'. Skeletal hyphae dextrinoid

6. Pores $6-8 / \mathrm{mm}$

7. Multiple clamp connections present

A. bracei

7'. Multiple clamp connections absent

A. efibulatus

8. Clamps present

A. iobapha

8'. Clamp absent 9

8. Basidiospores subglobose, $3.5-3.9 \times 2.7-3.2 \mu \mathrm{m}$

A. casuarinicola

8'. Basidiospores ellipsoid, 4-6 × 3-4.2 $\mu \mathrm{m}$ A. rubellus

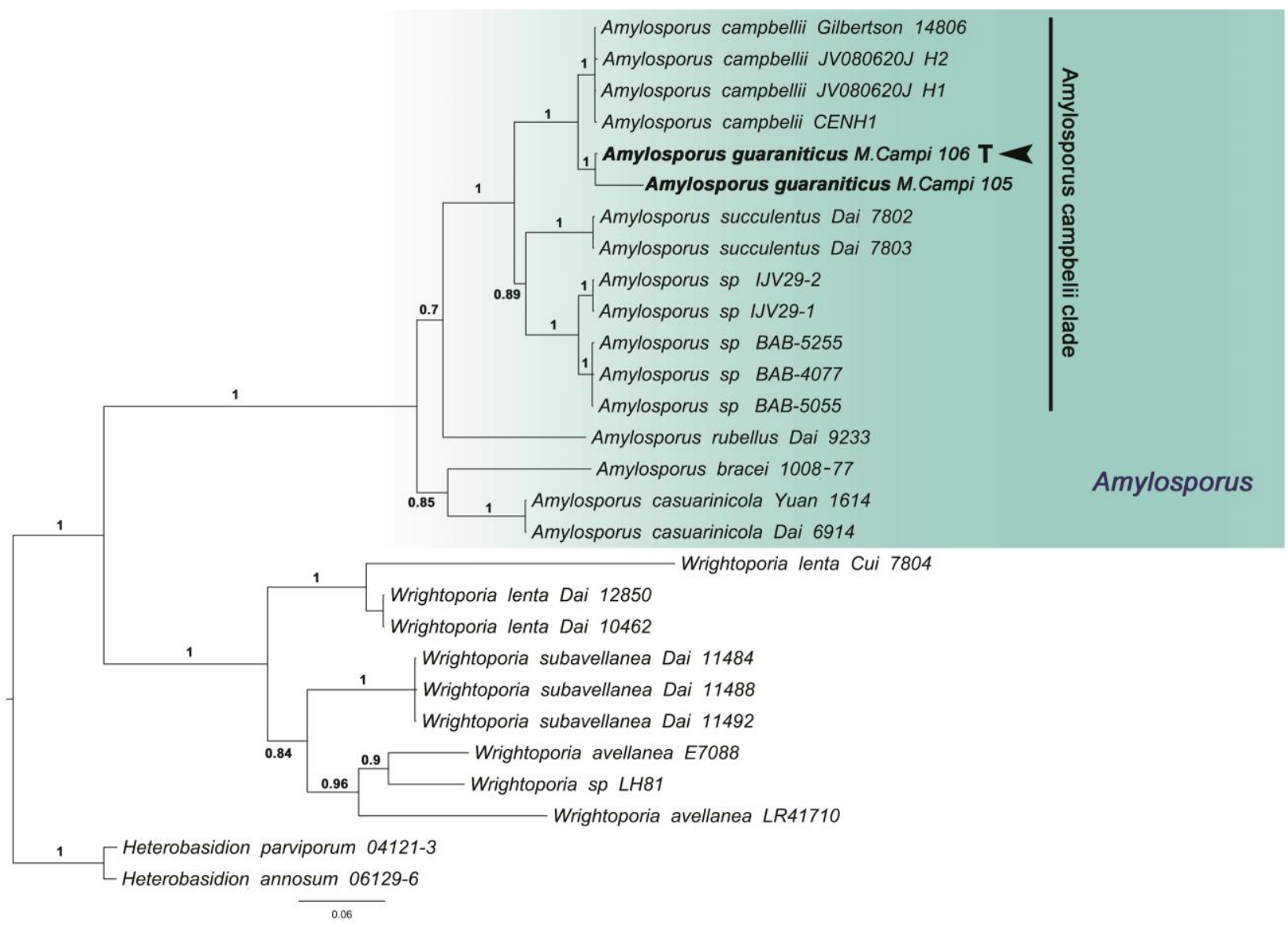

Figure 1. Strict consensus tree from Bayesian inference of the combined ITS-LSU dataset illustrating the phylogenetic relationships of Amylosporus within Wrightoporiaceae. The new species specimens from which new sequences were obtained in this work are in boldface. $\mathbf{T}<=$ type specimen. 
Table 1 List of species, collections, and GenBank accession numbers for the ITS and LSU sequences used in the phylogenetic analyses. n/d= no described; $\mathrm{n} / \mathrm{i}=$ no identified

\begin{tabular}{|c|c|c|c|}
\hline Species & Substrate & GenBank ac & cesion $\mathrm{N}^{\circ}$ \\
\hline Specimen $\mathrm{N}^{\circ}$, Locality & & ITS & LSU \\
\hline Amylosporus bracei (Murrill) A. David \& Rajchenb. & & & \\
\hline 1008/77, USA & Angiosperm & KM267724 & KJ807076 \\
\hline Amylosporus casuarinicola (Y.C. Dai \& B.K. Cui) Y.C. Dai et al. & & & \\
\hline Dai 6914/BJFC 2760, China, Guangxi Autonomous Region, Beihai, & Living tree of Casuarina equisetifolia & KJ807068 & \\
\hline Yuan 1614/IFP 12866, China, Yunnan Province, Xi-Shuang-Banna & Fallen angiosperm trunk & KM107862 & \\
\hline Amylosporus campbelli (Berk.) Ryvarden & & & \\
\hline JV080620J-H1, Jamaica & Angiosperm & JF692200 & KJ807077 \\
\hline JV080620J-H2, Jamaica & Angiosperm & JF692201 & KJ807077 \\
\hline Gilbertson 14806, USA & $\mathrm{n} / \mathrm{d}$ & KM107861 & KM107879 \\
\hline CENH1, Puerto Rico, & Orchid roots & KU847468 & \\
\hline Amylosporus guaraniticus Campi \& Robledo & & & \\
\hline M. Campi 106 (FACEN 3422), Paraguay, Asunción (T) & $\mathrm{n} / \mathrm{i}$ & MF377528 & MF377529 \\
\hline M. Campi 105 (FACEN 3421), Paraguay, Asunción & $\mathrm{n} / \mathrm{i}$ & MF377530 & \\
\hline Amylosporus rubellus (Y.C. Dai) Y.C. Dai, Jia J. Chen \& B.K. Cui & & & \\
\hline Dai 9233/IFP 12318, China, Beijing, Xiangshan & Rotten wood of Koelreuteria sp & KJ807071 & KJ807084 \\
\hline Amylosporus succulentus Jia J. Chen \& L.L. Shen 2014 & & & \\
\hline Dai 7802/BJFC 15731 China & Lawn & KM213669 & KM213671 \\
\hline Dai 7803/BJFC 15732, China & Lawn & KM213668 & KM213670 \\
\hline Amylosporus sp. & & & \\
\hline IJV29-1, Tanzania & $\mathrm{n} / \mathrm{d}$ & KM851314 & KM593892 \\
\hline IJV29-2, Tanzania & $\mathrm{n} / \mathrm{d}$ & KM851315 & KM593893 \\
\hline BAB-5255, India & $\mathrm{n} / \mathrm{d}$ & KT186196 & \\
\hline BAB-4077, India & $\mathrm{n} / \mathrm{d}$ & KJ670296 & \\
\hline BAB-5055, India & $\mathrm{n} / \mathrm{d}$ & KR155100 & \\
\hline Wrightoporia avellanea (Bres.) Pouzar & & & \\
\hline LR 41710, Jamaica & $\mathrm{n} / \mathrm{d}$ & AF506488 & AF506488 \\
\hline E 7088, Indonesia & $\mathrm{n} / \mathrm{d}$ & AJ537507 & AJ53750 \\
\hline
\end{tabular}


Table 1 List of species, collections, and GenBank accession numbers for the ITS and LSU sequences used in the phylogenetic analyses. $\mathrm{n} / \mathrm{d}=$ no described; $\mathrm{n} / \mathrm{i}=$ no identified

\begin{tabular}{|c|c|c|c|}
\hline \multirow{2}{*}{$\begin{array}{l}\text { Species } \\
\text { Specimen } \mathrm{N}^{\circ}, \text { Locality }\end{array}$} & \multirow[t]{2}{*}{ Substrate } & \multicolumn{2}{|c|}{ GenBank accesion $\mathrm{N}^{\circ}$} \\
\hline & & ITS & LSU \\
\hline \multicolumn{4}{|l|}{ Wrightoporia lenta (Overh. \& J. Lowe) Pouzar } \\
\hline Dai 10462/ BJFC 4711, China, Jiangxi Province, Fenyi County & Rotten wood of Cunninghamia & KJ513291 & KJ807082 \\
\hline Dai 12850/BJFC 13139, Heilongjiang Province, & Stump of Picea $\mathrm{sp}$ & KJ513295 & KJ807085 \\
\hline Cui 7804, China, Jiangxi Province, Fenyi County & Stump of Cunninghamia sp & KJ513292 & KJ807081 \\
\hline \multicolumn{4}{|l|}{ Wrightoporia subavellanea Jia J. Chen \& B.K. Cui } \\
\hline Dai 11484/ BJFC 7352, China, Guangxi Autonomous Region & Rotten wood of Pinus & KJ513295 & KJ807085 \\
\hline Dai 11488/ BJFC 7356, China, Guangxi Autonomous Region & Rotten wood of Pinus & KJ513296 & KJ807086 \\
\hline Dai 11492/ BJFC 7360, China, Guangxi Autonomous Region & Rotten wood of Pinus & KJ513297 & KJ807087 \\
\hline \multicolumn{4}{|l|}{ Wrightoporia sp. } \\
\hline LH81, Malasya, Sarawak Lambir Hills National Park & Ectomycorrhizal root tip & GQ268628 & \\
\hline Heterobasidion annosum (Fr.) Bref. & & KJ583211 & KJ583225 \\
\hline 06129/6, Russia & Pinus sylvestris & & \\
\hline Heterobasidion parviporum Niemelä \& Korhonen & & KJ583212 & KJ583226 \\
\hline $04121 / 3$, Finland & Picea abies & & \\
\hline
\end{tabular}

\section{Discussion}

Amylosporus guaraniticus is characterized by fleshy, whitish pileate basidiomata, with both simple septate and double to multiple clamped generative hyphae, hyaline skeletal hyphae without reaction in Melzer's reagent, presence of gloeoplerous hyphae; and ovoid to ellipsoid, asperulate strongly amyloid basidiospores, 4-6.5 × 3-4.5 $\mu \mathrm{m}$.

Morphologically and phylogenetically A. guaraniticus is related to A. campbellii and A. succulentus within the 'A. campbellii clade'. Amylosporus campbellii presents similar basidiospore size, simple septate and double to multiple clamped generative hyphae, the presence of gloeoplerous hyphae and skeletal hyphae without reaction in Melzer's reagent (Table 2). However, A. guaraniticus develops sessile basidiomata, broadly attached and imbricated while $A$. campbellii develops stipitate to subestipitate basidiomata single or in clusters

Species within 'A. campbellii clade' present particular substrata. Amylosporus cambellii has been described with a terrestrial growth on grasslands, being a possible grass parasite (Ryvarden \& Johansen 1980). One of the specimens of A. cambpelii included in our analyses [CENH1, from Puerto Rico] stands out as it has been isolated from orchids roots (Table 1). Amylosporus succulentus [previously recorded as A. campbelli (Dai 2007)] grow on grass. Amylosporus guaraniticus was collected inside a sump, arising from the concrete wall (Fig. 2A-B), located in a corridor of a building distanced at least 30 meters from the nearest open place with grass and trees. 


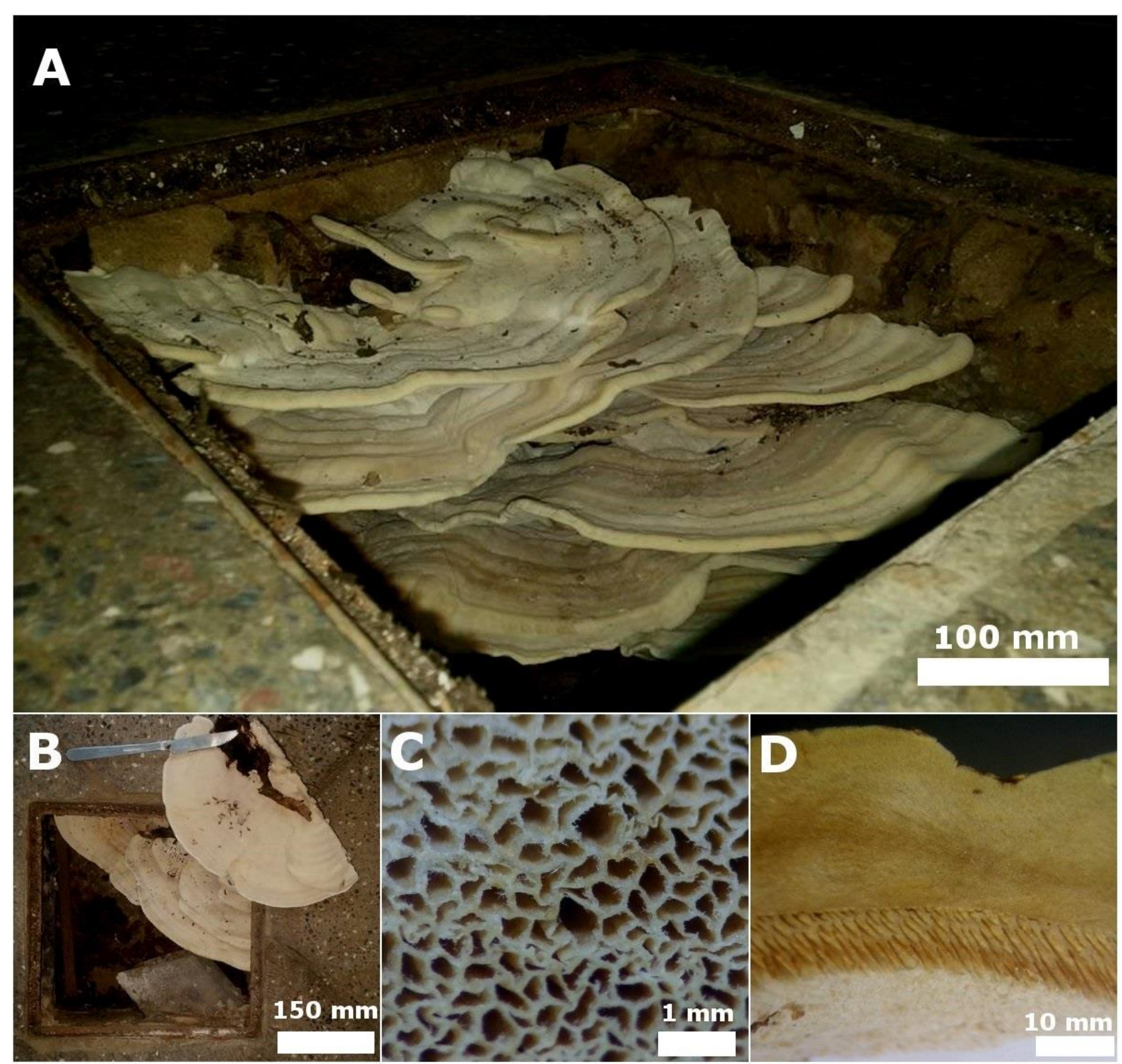

Figure 2. Amylosporus guaraniticus (FACEN 003422, HOLOTYPE) macroscopical features. A-B general view inside a sump, $\mathbf{C}$ close up of pores, $\mathbf{D}$ longitudinal section showing context ant tube layer

The mycelium could be living on a buried log or trunk, decaying organic matter, or be related to living tree roots that follow pipes, however it could not be verified so far. The definition of Amylosporus as a white rot genus (Chen et al. 2016) has to be reconsidered.

Our phylogenetic reconstructions recovered Amylosporus as monophyletic clade within the Wrightoporiaceae (Figure 1), according with previous results (Chen et al. 2016). However, five species are currently combined in Amylosporus so far not included into phylogentice analyses, i.e. A. auxiliadorae Drechsler-Santos \& Ryvarden, A. daedaliformis G.Y. Zheng \& Z.S. Bi, A. efibulatus (I. Lindblad \& Ryvarden) Y.C. Dai, Jia J. Chen \& B.K, A. iobaphus (Pat.) A. David \& Rajchenb. and A. ryvardenii Stalpers. Amylosporus auxiliadorae presents morphological characteristics and habit (growing on ground) suggesting a relationship with 'Amylosporus campbelli clade'. Amylosporus daedaliformis has been described with basidiospores IKI-, suggesting phylogenetic relationships outside Amylosporus. Amylosporus efibulatus and A. ryvardenii (三 Rigidoporiopsis amylospora Ryvarden) develop resupinate and adnate basidiomata with mono- to dimitic simple septate hyphal system (Ryvarden \& Johansen 1980, Ryvarden 2000). Amylosporus iobaphus develops resupinate and widely effused basidiomata, with a dimitic hyphal system composed by simple septate and multi-clamped generative hyphae and dextrinoid skeletal 
hyphae (David \& Rajchenberg 1985). Further molecular evidence is desirable to depict the relationships of these species within Wrightoporiaceae.

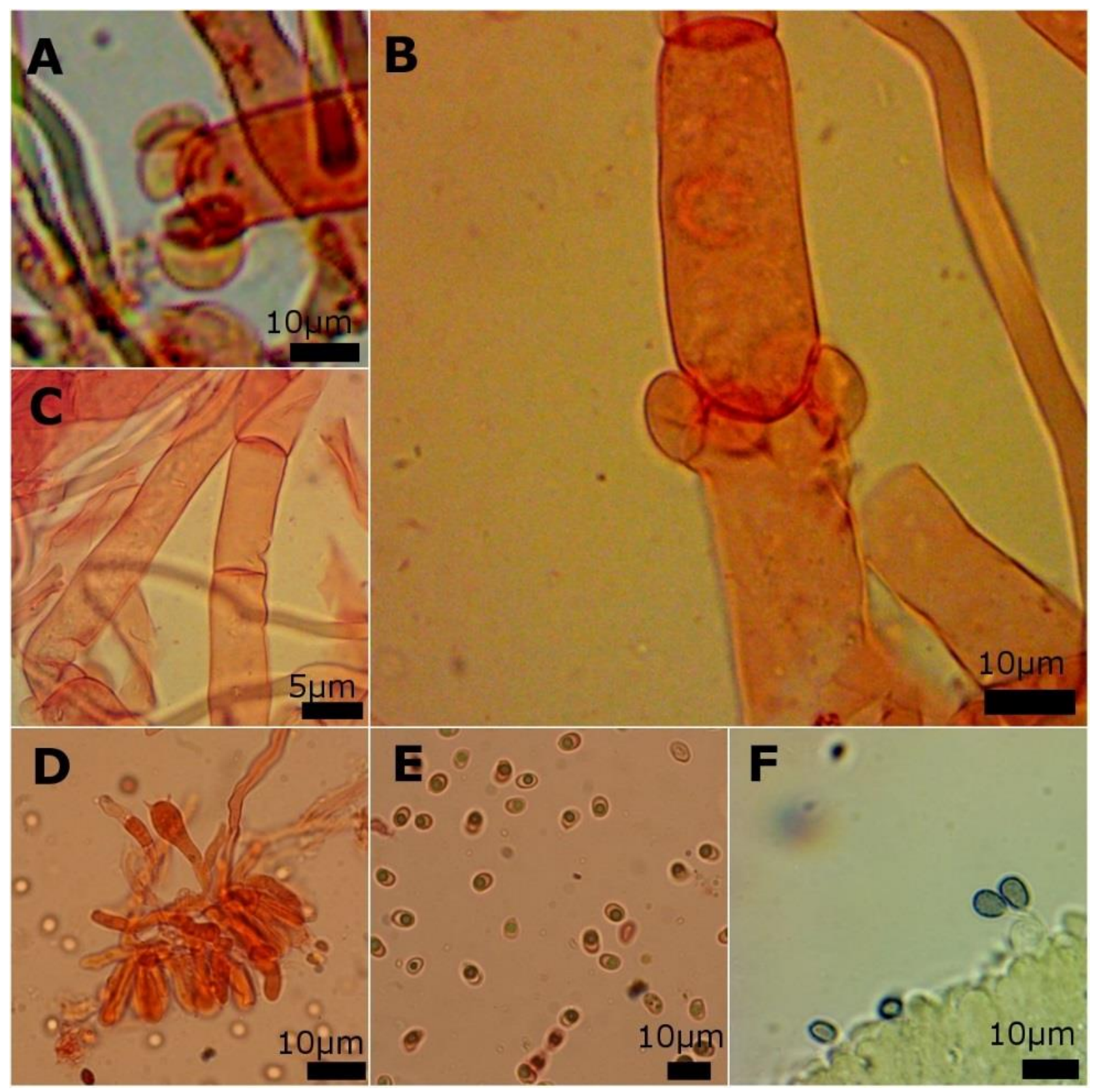

Figure 3 - Amylosporus guaraniticus (FACEN 003422, HOLOTYPE) microscopical features A-B multiple clamped generative hyphae. $\mathbf{C}$ simple septate generative hyphae. D Basidia. E Basidiospores in $\mathrm{KOH}+$ Floxine, showing refringent central guttula. F Basidiospores in Melzer's reagent.

\section{Acknowledgements}

Authors wish to acknowledge the assistance of Consejo Nacional de Ciencias y Tecnología CONACYT through the project of Iniciación Científica 14-INV-353 "CONTRIBUCIÓN AL REGISTRO DE MACROMICETOS DEL CAMPUS UNIVERSITARIO DE SAN LORENZO”, Consejo Nacional de Investigaciones Científicas y Técnicas (CONICET), Universidad Nacional de Asunción-Facultad de Ciencias Exactas y Naturales and Universidad Nacional de Córdoba, and Instituto Misionero de Biodiversidad (IMiBio) all of them support facilities used in this work. Financial support was provided by FONCYT (PICT-2015-0830) to G. Robledo. Authors kindly acknowledge Idea Wild for their support with technical equipment; and L. Caeiro (CPA CONICET-UNC) and D. Franchi for their technical support. 


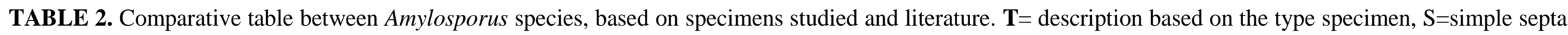
present, $\mathrm{MC}=$ multiple clamp connections present, $\mathrm{n} / \mathrm{d}=$ no described, $*$ size range based on 30 measurements.

\begin{tabular}{|c|c|c|c|c|c|c|}
\hline Species & Basidiomata & Pores & \multicolumn{3}{|c|}{ Hyphae } & \multirow{2}{*}{$\begin{array}{c}\text { Basidiospores } \\
\text { Size }(\mu \mathrm{m}) \\
\end{array}$} \\
\hline Specimens / Reference & & Size $(p / \mathbf{m m}) ;$ shape & septa & skeletal & GH & \\
\hline \multicolumn{7}{|l|}{ Amylosporus campbellii } \\
\hline Ryvarden \& Johansen (1980) & A, Stipitate & $2-4$, round to angular & $\mathrm{S}, \mathrm{MC}$ & IKI- & + & $4-5 \times 2.5-4$ \\
\hline \multicolumn{7}{|l|}{ Amylosporus guaraniticus } \\
\hline This work $(\mathbf{T})$ & A, Pileate & 2-3; angular & $\mathrm{S}, \mathrm{MC}$ & IKI- & + & $4-5.5 \times 3-4 *$ \\
\hline \multicolumn{7}{|l|}{ Amylosporus succulentus } \\
\hline Chen \& Shen (2014) (T) & A, Stipitate & 2-4, angular & $\mathrm{S}, \mathrm{MC}$ & Dextrinoid & + & $4.2-5.2 \times 3-3.8$ \\
\hline \multicolumn{7}{|l|}{ Amylosporus bracei } \\
\hline Rajchenberg (1983) as A. wrightii & A, P Sessile-Resupinate & $7-8, \mathrm{n} / \mathrm{d}$ & $\mathrm{S}, \mathrm{MC}$ & Dextrinoid & - & $3.1-3.6 \times 2.6$ \\
\hline Amylosporus casuarinicola & & & & & & \\
\hline Dai \& Cui (2006) & P, Sessile-Resupinate & $3-4$, round to angular & $\mathrm{S}$ & Dextrinoid & - & $3.5-3.9 \times 2.7-3.2$ \\
\hline \multicolumn{7}{|l|}{ Amylosporus efibulatus } \\
\hline Lindblad \& Ryvarden (1999) (T) & A, Sessile-Resupinate & $6-8$, round & $\mathrm{S}$ & IKI- & - & $3-3.5$ \\
\hline \multicolumn{7}{|l|}{ Amylosporus auxiliadorae } \\
\hline Drechsler-Santoset al. (2016) (T) & A, Stipitate & 3-6, irregular & $\mathrm{S}, \mathrm{MC}$ & Dextrinoid & + & $4.0-5.0 \times 2.5-4.0$ \\
\hline \multicolumn{7}{|l|}{ Amylosporus iobaphus } \\
\hline Ryvarden (1983) (T) & A, Sessile-Resupinate & 3-4, irregular, angular & $\mathrm{S}, \mathrm{MC}$ & Dextrinoid & - & $3-4.5 \times 3-4$ \\
\hline \multicolumn{7}{|l|}{ Amylosporus ryvardenii } \\
\hline $\begin{array}{l}\text { Johansen \& Ryvarden (1979) as } \\
\text { Rigidoporopsis amylospora }(\mathbf{T})\end{array}$ & A, Sessile-Resupinate, & 4-6, circular & $\mathrm{S}$ & IKI- & - & $4-5 \times 2.5-3$ \\
\hline \multicolumn{7}{|l|}{ Amylosporus rubellus } \\
\hline Dai (1995) & A, Sessile-Resupinate to EF & $3-4$, round to angular & $\mathrm{S}$ & Dextrinoid & + & $4-6 \times 3-4.2$ \\
\hline
\end{tabular}




\section{References}

Chen JJ, Shen LL. 2014 - Amylosporus succulentus sp. nov. (Russulales, Basidiomycota) evidenced by morphological characters and phylogenetic analysis. Cryptogamie Mycologie 35, 271-282.

Chen JJ, Cui BK, Dai YC. 2016 - Global diversity and molecular systematics of Wrightoporia s.1. (Russulales, Basidiomycota). Persoonia 37, 21-36.

Dai YC. 1995 - A new species of Wrightoporia (Basidiomycetes) from China. Karstenia 35, 8589.

Dai YC, Cui BK. 2006 - Two new species of Wrightoporia (Basidiomycota, Aphyllophorales) from southern China. Mycotaxon 96, 199-206.

Dai YC. 2007 - Amylosporus campbellii, a noteworthy polypore new to Southeast Asia. Czech Mycology 59, 171-175.

David A, Rajchenberg M. 1985 - Pore fungi from French Antilles and Guiana. Mycotaxon 22, 285-325.

Doyle J. 1991 - DNA protocols for plants. Springer, New York.

Drechsler-Santos ER, Salvador-Montoya CA, Ryvarden L. 2016 - Studies in Neotropical polypores 41, a new species of Amylosporus from Caatinga dry woodlands, Brazil. Synopsis Fungorum $35,4-8$.

Gardes M, Bruns TD. 1993 - ITS primers with enhanced specificity for basidiomycetes application to the identification of mycorrhizae and rusts. Molecular Ecology 2, 113-118.

Gómez-Montoya N, Drechsler-Santos ER, Ferreira Lopes V, Tomšovský M, Urcelay C, Robledo GL. 2017 - New insights on Trametopsis Tomšovský (Polyporales Gäum) based on phylogenetic evidences and morphological analyses of neotropical species. Phytotaxa (In press).

Hall TA. 1999 - BioEdit: a user-friendly biological sequence alignment editor and analysis program for Windows 95/98/NT. In Nucleic acids symposium series 41, 95-98.

Hopple JS, Vilgalys R. 1999 - Phylogenetic relationships in the mushroom genus Coprinus and dark-spored allies based on sequence data from the nuclear gene coding for the large ribosomal subunit RNA: divergent domains, outgroups, and monophyly. Molecular Phylogenetics and Evolution 13, 1-19.

Huelsenbeck JP, Ronquist F. 2001 - MrBAYES: Bayesian inference of phylogenetic trees. Bioinformatics 17, 754-755.

Johansen I, Ryvarden L. 1979 - Studies in the aphyllophorales of Africa: VII. Some new genera and species in the Polyporaceae. Transactions of the British Mycological Society 72, 189199.

Lindblad I, Ryvarden L. 1999. Studies in neotropical polypores. 3. New and interesting Basidiomycetes (Poriales) from Costa Rica. Mycotaxon 71,335-359.

Nei M, Kumar S. 2000 - Molecular evolution and phylogenetics. Oxford University Press, Oxford.

Rajchenberg M. 1983 - New South American resupinate polypores. Mycotaxon 16, 500-506.

Ryvarden L. 1973 - New genera in the Polyporaceae. Nordic Journal of Botany 20, 1-5.

Ryvarden L, Johansen I. 1980 - A preliminary Polypore flora of East Africa. Fungiflora. Oslo, Norway.

Ryvarden L. 1983 - Type studies in the Polyporaceae 14. Species described by N. Patouilliard, either alone or with other mycologists. Occasional Papers of the Farlow Herbarium. 18, 1-39.

Ryvarden, L. 2000 - Studies in neotropical polypores 7. Wrightoporia (Hericiaceae, Basidiomycetes) in tropical America. Karstenia. 40, 153-158. 